Teología y Vida, Vol. XLVI (2005), 374 -388

María Eugenia Góngora D.

Profesora Titular Departamento Literatura

Universidad de Chile

\title{
Escritura e imagen visionaria en el liber divinorum operum de Hildegard de Bingen*
}

Tus ojos contemplarán a un rey en su belleza, verán una tierra dilatada.

Isaías 33, 17

Ahora vemos como en un espejo, en palabras oscuras; mas entonces veremos cara a cara. Ahora conozco en parte, pero entonces conoceré como soy conocido.

1 Corintios, 13, 12

En este estudio quiero referirme a los escritos de Hildegard de Bingen y en particular a su último gran libro visionario, el Liber divinorum operum, centrando la atención en algunos aspectos de su escritura y de sus imágenes visionarias.

El estatuto de las obras medievales que se presentan explícitamente como 'escritura de revelación' (así como de aquellas que se presentan como testimonio de un sueño) es sin duda un objeto de estudio importante en cuanto a los problemas de interpretación y lectura que ellas suscitan: 'ahora vemos como en un espejo, en palabras oscuras'.

Autoría, recepción y tradición profética, por una parte, y las relaciones entre 'imagen visionaria' y texto, 'revelación' y conocimiento, son algunos de los asuntos problemáticos que surgen de inmediato en la consideración de obras como el Liber divinorum operum (1) "que Hildegard de Bingen (2) compuso en dos etapas, a partir de 1163 y hasta 1170 , con la ayuda de su secretario Volmar (muerto en 1173) y que luego pudo completar hacia 1174 (3).

(*) Este estudio está escrito en el marco del Proyecto Fondecyt No 1030732: "Autoría y tradición profética en el Liber divinorum operum de Hildegard de Bingen (1098-1179)"

(1) Hildegardis Bingensis Liber divinorum operum, ed. Albert Derolez, / Peter Dronke (CC CM 92, Turnhout, Brepols 1996. Editio princeps: Card. G.D. Mansi en su Miscellanea de la obra de Etienne Baluze, 4 tomos, Lucca 1761. De ahora en adelante, $L D O$.

(2) La religiosa alemana Hildegard de Bingen (1098-1179) fue autora de tres compendios de relatos visionarios: Scivias, Liber vitae meritorum y Liber divinorum operum así como de un ciclo de canciones (la Symphonia armonie celestium revelationis), un tratado de las enfermedades y sus remedios (Causae et curae), una Physica que incluye un Bestiario, dos hagiografías y tratados doctrinales, así como de un vasto epistolario que comprende actualmente casi cuatrocientas cartas.

(3) Hildegard recibió el apoyo de su sobrino Wezzelin, provoste en Colonia, y muy especialmente del abad Ludwig de St. Eucharius (Trier), quien más tarde encomendaría a Theoderich, magister 
Esta obra (y el resto de sus escritos visionarios (4), líricos (5) y aún epistolares (6)) ha sido asumida en el pasado con algún grado de dificultad por las distintas tradiciones disciplinarias que han intentado hacerse cargo de ella y, como lo planteó Christel Meier (7) hace ya casi veinte años, ni la Teología ni la Literatura o la Historia del Arte (podríamos añadir nosotros: ni la filosofía o la historia medievales) han podido otorgar a la obra de Hildegard un 'lugar' preciso en su disciplina. Desde la filología y los estudios literarios afines, por cierto, ha sido casi siempre (8) interpretada en la perspectiva que resulta a primera vista más fácilmente aprehensible, es decir, la de la creación alegórica (9), entendida esta última, muchas veces, en

scholarum del monasterio cisterciense de Echternach -geográficamente muy cercano a Bingen- la composición de la más completa hagiografía de Hildegard, la Vita Hildegardis virginis (Monika Klaes, ed., CC CM 126, Brepols, Turnhout 1993).

(4) Liber Scivias (compuesto entre 1141 y 1151: A. Führkötter /A.Carlevaris, eds., CC CM 43 y 43 A, Turnhout, Brepols 1978) y Liber vitae meritorum (compuesto entre 1158 y 1163: A. Carlevaris, ed., CC CM 90, Turnhout, Brepols 1995). Ambos textos, así como la mayor parte del LDO fueron compuestos con ayuda de su secretario Volmar.

(5) Saint Hildegard of Bingen. Symphonia. Critical edition of the Symphonia armonie celestium revelationum, B. Newman, Cornell University Press, Ithaca \& London 1988. Edición castellana: Hildegard de Bingen. Sinfonía de la armonía de las revelaciones celestiales, M. I. Flisfisch et al., Madrid, Trotta 2003.

(6) Hildegardis Bingensis Epistolarium I. Pars prima I-XC. II. Pars secunda XCI-CCL R, ed. Liven van Acker, CC CM 91 y 91 A, Brepols, Turnholt 1991-1993; Epistolarium III, CCLI-CCCXC, ed. Monika Klaes CC CM PB 91 B, Brepols, Turnholt 2001.

(7) Meier, Ch., Eriugena im Nonnenkloster? Überlegungen zum Verhältnis von Prophetentum und Werkggestalt in den figmenta prophetica Hildegards von Bingen', in Frühmittelalterliche Studien 19, 1985, p. 468, n. 11, (cit. Por Michael Zöller, "Aufschein des Neuen im Alten. Das Buch Scivias der Hildegard von Bingen im geistes-geschichtlichen Kontext des zwölften Jahrhundertsein gattungsspezifische Einordnung" in Hildegard von Bingen in ihren historischen Umfeld, A. Haverkamp, ed., Verlag Philipp von Zabern, Mainz 2000, pp. 271-297 (p. 271).

(8) Una excepción reciente la constituye la línea de trabajo iniciada por Victoria Cirlot y sus estudios de la actividad visionaria, especialmente en la perspectiva del pensamiento de Henry Corbin. Un resumen de sus proposiciones se encuentra en "Hildegard von Bingen y Juan de Patmos: la experiencia visionaria en el siglo XII" en Revista Chilena de Literatura 63, noviembre 2003, pp. 109-129. Si bien no estudia directamente la obra de Hildegard, es también importante en este sentido la perspectiva que ofrece la compilación de ensayos de Alois Haas: Visión en azul. Estudios de mística europea, Ediciones Siruela, Madrid 1999 Cf. esp. 'Sueño y visión en la mística alemana', que propone un acercamiento específicamente teológico a los escritos y a la devoción de las monjas como Margarethe Ebner y las religiosas de los conventos de de Adelhausen, Katharinental, Engelthal, Unterlinden y otros (pp. 13-31).

(9) Para una exposición detallada de las variadas definiciones teóricas del alegorismo medieval en los autores de los siglos XII y XIII (así como para una descripción del macrocosmos y el microcosmos en el $L D O$ de Hildegard de Bingen), ver Edgar de Bruyne, Estética Medieval, vol. II (Madrid, Gredos 1959), en particular el cap. VII, 'La teoría del alegorismo', pp. 316-384 (esp. 327371). Para De Bruyne, "la teoría del alegorismo ha sido elaborada ante todo por los teólogos. El ‘sensus allegoricus' es en la Edad Media una noción teológica antes que literaria” (p. 318). Santo Tomás, sin embargo, afirma que cuando "los autores profanos usan alegorías, expresiones figuradas y fábulas [hay que entenderlas] en sentido moral. Mediante cuentos ficticios, extraídos de la vida de los animales, nos incitan a bien vivir; a través de los mitos nos presentan las formas naturales bajo formas plásticas" ("Poeticae artis est veritatem rerum aliquibus similitudinibus fictis designare"), (Quodl., VII, 9, 6, a.16, cit. por De Bruyne, op. cit., p. 321). El estudio clásico sobre la exégesis bíblica en la Edad Media es el de Henri de Lubac: Exegèse médiévale: les quatre sens de l'Ecriture, 4 vols., Aubier, Paris 1959-1964. Para De Lubac, los límites metodológicos entre teología y exégesis bíblica no están claros en los autores del siglo XII (p. 111). Vale la pena recordar aquí los versos sobre los cuatro sentidos de la escritura, cuya autoría y datación discute también este autor: "Litera gesta docet, quid credas allegoria, morales quid agas, quo tendas anagogia", habitualmente atribuidos a Nicolas de Lyra (ca. 1330). 
un sentido aplicable a las obras literarias más que en el 'sentido alegórico' característico de la exégesis teológica de los textos bíblicos. Son sin duda ejemplares en este sentido los trabajos de Peter Dronke (10), quien ha trabajado la obra de Hildegard también desde un punto de vista filológico, junto a Albert Derolez, precisamente en la edición crítica del $L D O$. Por otra parte, la preocupación por el 'lugar' específico de la obra de Hildegard en alguna de las disciplinas tradicionales es probablemente menos urgente ahora que hace dos décadas; una buena muestra la constituyen en este sentido los recientes estudios históricos sobre la obra de Hildegard y su recepción (11), así como el lugar que su figura ocupa en los trabajos de estudiosos de la historia de la devoción medieval (12).

Nuestra propia lectura presupone, por cierto, la existencia de una actividad alegórica (13) en la escritura de Hildegard, entendida esta actividad alegórica en un sentido amplio, pero pretende asimismo avanzar en la interpretación de esta asumiendo plenamente su especificidad exegética y su especificidad visionaria (14). Como sabemos, para Peter Dinzelbacher, las visiones de Hildegard "constituyen un conjunto errático" y ocupan por lo mismo un lugar especial en la literatura visionaria. Esto se debería a que, en su concepción del género, la experiencia visionaria está necesariamente relacionada -en primer lugar- con el sueño o con el éxtasis, mientras que Hildegard, por su parte, rechaza explícitamente en todos sus escritos que sus visiones estén relacionadas con alguno de estos estados. En su estudio,

(10) En este contexto, es ilustrativa la discusión de Dronke sobre las relaciones entre 'Simbolismo' y 'Alegoría' tal como J. Huizinga las plantea en El Otoño de la Edad Media, inscritas como problema de tradición goethiana: el símbolo visto como 'idea' y la alegoría como 'concepto': cf. Dronke, P., "Arbor Caritatis" en Intellectuals and Poets in Medieval Europe, Edizione di Storia e Letteratura, Roma 1992, pp. 103-141 (p. 103); cf. también su discusión sobre la alegoría en los pensadores del siglo XII (en particular los de la Escuela de Chartres), en la ya mencionada compilación Intellectuals and Poets, "Bernardus silvestris, Natura, and Personification" (pp. 4161) así como "Integumenta Virgilii" (63-78). Cf. también estudios anteriores sobre el alegorismo en su Fabula, J. Brill, Leiden-Köln 1974, (pp. 120-122).

(11) Un buen ejemplo lo constituye el volumen de estudios editado por el historiador Alfred Haverkamp, quien editó las actas del Congreso internacional que se realizó en Bingen en 1998: Hildegard von Bingen in ihrem historischen Umfeld, Verlag Pilipp von Zabern, Mainz 2000. En esta publicación encontramos, entre otras, las importantes colaboraciones de Angela Carlevaris, Giles Constable, Constant J. Mews, Peter Dronke, Bernard McGinn, Jean-Claude Schmitt, John van Engen, Albert Derolez, Laurence Moulinier, Hans-Joachim Schmidt, Michael Embach y MarcAeilko Aris (dedicados estos tres últimos estudios a la recepción de la obra de Hildegard hasta el siglo XX).

(12) Victoria Cirlot y Alois Haas (ver supra n. 8), Bernard McGinn, "Hildegard of Bingen as Visionary and Exegete" in Hildegard of Bingen in ihrem historischen Umfeld" Verlag Pilipp von Zabern, Mainz 2000, pp. 320-350; Caroline Walker Bynum, Jesus as Mother. Studies in the Spirituality of the High Middle Ages, University of California Press, Berkeley-Los Angeles-London 1982; Barbara Newman, Sister of Wisdom. Hildegard of Bingen's Theology of the Feminine, University of Carlifornia Press, Berkely-Los Angeles, 1987. Newman es también la editora de la ya mencionada versión bilingüe y los comentarios de la obra lírica de Hildegard, Symphonia. A critical edition of the Symphonia armonie celestium revelationis; compiló asimismo una colección de ensayos sobre la obra de Hildegard titulada Voice of the Living Light. Hildegard of Bingen and her World, Barbara Newman, ed., University of California Press, Berkeley \& Los Angeles, 1998.

(13) Para un estudio de la alegoría en Scivias y para una discusión genérica de esa obra en el contexto de la escritura teológico-espiritual, ver Michael Zöller, "Aufschein des Neuen im Alten" (cf. n. 7, esp. pp. 276-287).

(14) En el artículo ya citado, McGinn discute las relaciones entre exégesis, profecía y visión en la obra de Hildegard (McGinn, op. cit., ver supra n. 12). 
Dinzelbacher diferencia dos 'tipos' de relatos, ninguno de los cuales corresponde a los textos visionarios de Hildegard: por una parte, las descripciones visionarias del 'Otro Mundo', propias sobre todo de la temprana Edad Media y, por otra, los encuentros con el Señor, especialmente marcados por la mística amorosa, cercana a la imaginería del Cantar de los Cantares, particularmente frecuentes en la Edad Media tardía (15). Para el mismo Dinzelbacher, en cambio, la serie más o menos abierta de visiones individuales que encontramos en la obra de Hildegard, constituye más bien una "teología hecha imágenes", lo que también la diferenciaría de los 'tipos' literarios anteriormente mencionados. Por último, en su antología de textos visionarios (16), Dinzelbacher afirma nuevamente que la grandiosa Historia simbólica de la Salvación propuesta por Hildegard fue única, no solo por su contenido tan variado y bien construido, sino por su inspiración, es decir, por su rechazo del sueño y del éxtasis como condición para su acceso a la visión.

En los tres libros visionarios de Hildegard nos encontramos con una escritura que relata y representa -gracias a su estructura bipartita- (17) una visión/ audición; esta última otorga a su vez un sentido a los libros de la Sagrada Escritura (18), pero sobre todo a los textos visionarios de la propia autora (19). Las 'audiciones' pretenden hacer comprensible el sentido 'intelectual', 'místico', o 'secreto', de las propias visiones y de otros textos (20) y, si bien Hildegard se refiere a menudo en su obra a lo que ella denomina una visio mystica (21), hay que entender esta expresión

(15) Peter Dinzelbacher, Vision und Visionsliteratur im Mittelalter, Monographien zur Geschichte des Mittelalters 23, Stuttgart 1981 (cf. pp. 5, 18 y ss, 106).

(16) Peter Dinzelbacher, Mittelalterliche Visionsliteratur. Eine Anthologie, Wissenschaftliche Buchgesellschaft, Darmstadt 1989, p. 27.

(17) En los tres libros visionarios se repite la misma estructura: la presentación de la visión está seguida de una interpretación (en muchos casos una verdadera exégesis textual, casi frase a frase), que es atribuida a la voz divina escuchada por la visionaria.

(18) Scivias, Führkötter / Carlevaris, Protestificatio, p. 3. Prólogo: "Sucedió en el año 1141 después de la encarnación de Jesucristo. A la edad de cuarenta y dos años y siete meses, vino del cielo abierto una luz ígnea que se derramó como una llama en todo mi cerebro, en todo mi corazón y en todo mi pecho. No ardía, solo era caliente, del mismo modo que calienta el sol todo aquello sobre lo que pone sus rayos. Y de pronto comprendí el sentido de los libros, de los salterios, de los evangelios y de otros volúmenes católicos, tanto del antiguo como del nuevo testamento, aun sin conocer las explicación de cada una de las palabras del texto, ni la división de las sílabas, ni los casos, ni los tiempos". Epistolarium, Van Acker, op. cit. Ep. I, p. CITAR Epístola a Bernardo de Clairvaux: “...Conozco el sentido interior de la exposición del Salterio, del Evangelio y de otros volúmenes, que me ha sido mostrado en esta visión. Como una llama ardiente conmovió mi pecho y mi alma enseñándome lo profundo de la exposición. Pero no me enseñó las letras que desconozco en lengua alemana. Solo sé leer en simplicidad y no descomponer el texto" (Traducciones de V. Cirlot, en su antología: Vida y Visiones de Hildegard von Bingen, Madrid, Ediciones Siruela 1997, pp. 198 (Scivias) y 123-124 (Epístola).

(19) Cf. Bernard McGinn, "Hildegard von Bingen as Visionary and Exegete"in Hildegard von Bingen in ihrem historischen Umfeld (ver supra, n. 12, p. 333).

(20) En el Scivias encontramos la afirmación divina sobre la revelación [a través de Hildegard ] de los secretos escondidos en los libros: "... sed ego qui sum dico per eum nova secreta et multa mystica quae hactenus in voluminibus latuerunt "(Scivias III, 11, 18, 387-389; A. Führkötter/A. Carlevaris, p. 586. Cf. De Bruyne, op. cit.)" "Lo que se entiende por alegorismo en la Edad Media se refiere, pues, según los teólogos, a la interpretación espiritual de lo real visible o histórico, considerado como la imagen o figura de un mundo sobrenatural, lleno de misterios" (p. 321).

(21) McGinn (op. cit. ver supra n. 12, pp. 326-337) describe sus formas de visión en relación con el pensamiento de San Agustín y establece una correspondencia entre estas 'visiones místicas' y las 'visiones espirituales' de San Agustín. Por otra parte, podría considerarse 'visión intelectual' 
como una 'visión espiritual' en el sentido agustiniano, en la que se revelan los misterios, los sentidos secretos de las obras de Dios a través de las imágenes visionarias (22).

Dada su influencia en el pensamiento medieval, es fundamental para nuestra comprensión de la obra de Hildegard tener en cuenta el pensamiento de San Agustín sobre qué sea una visión y, por otra parte, las tres clases de visiones que él distingue: la corporal y la espiritual -ambas visiones de imágenes- y la intelectual, que consiste más bien en una contemplación de las verdades sin la concurrencia de imágenes. Como sabemos, a partir del texto de san Pablo en el que habla de un hombre que fue transportado al tercer cielo, arrebatado al paraíso y oyó palabras inefables que no es dado expresar al hombre (II Corintios 12, 2-4), San Agustín discute sobre los géneros de visiones en el libro XII de su Del Génesis a la letra:

"Cuando se lee este precepto: Amarás a tu prójimo como a ti mismo, nos salen al paso tres clases distintas de visiones. Una es la de los ojos con los cuales se contemplan las letras; otra la del espíritu del hombre por la que se piensa en el prójimo ausente; la tercera tiene lugar en la mente atenta con la que se contempla la misma dilección. (...) El hombre, el árbol, el sol o cualquier otro cuerpo celeste o terrestre, hallándose presentes se ven en su forma, y ausentes, se contemplan en la imagen impresa en el alma, en la que se encuentran archivadas estas imágenes [en la memoria]. Mas el amor, ¿acaso se ve de un modo cuando está presente en su propia forma y de otro cuando está ausente en alguna imagen semejante a él? Ciertamente que no, puesto que se discierne por la mente, tanto cuanto ella puede(...) A la primera visión la llamamos corporal, porque se percibe por el cuerpo y se muestra en los sentidos corporales. A la segunda, espiritual, pues todo lo que no es cuerpo y, sin embargo, es algo, se llama rectamente espíritu y ciertamente no es cuerpo, aunque sea semejante al cuerpo la imagen del cuerpo ausente y la mirada con que se ve la imagen. La tercera clase de visión se llama intelectual, del origen de donde procede" (23).

Particularmente en el caso del $L D O$, la obra visionaria más madura compuesta por Hildegard, los textos nos quieren mostrar una imagen del mundo y del hombre,

aquella visión extraordinaria que Hildegard describe en un pasaje autobiográfico de la Vita, durante la cual su cuerpo se transformó y 'su conocimiento fue transmutado' gracias a la inspiración que cayó como gotas de lluvia sobre su alma, tal como el Espíritu Santo inspiró a San Juan Evangelista cuando chupó la revelación del pecho de Jesús y se le revelaron los misterios escondidos y pudo decir: 'En el principio era el Verbo' (Vita II, 16) El término visio mystica parece haber sido usado por primera vez por San Jerónimo y también se encuentra en Gregorio el Grande. Juan Scoto Eriugena y Rabanus Maurus lo utilizan restringidamente y el término es usado más ampliamente en el siglo XII: Hildegard lo emplea 12 veces, Ricardo de San Víctor en ocho oportunidades. (Cf. p. 329, n. 20).

(22) Un estudio sobre el fenómeno de las visiones y profecías (y en particular de las llamadas 'revelaciones privadas') desde el punto de vista psicológico y de la teología católica es el de Karl Rahner SJ, Visiones y Profecías, trad. Española de M. Altolaguirre, Ediciones "Dinor", San Sebastián 1956.

(23) San Agustín, De Genesi ad Litteram, XII, 6, 15 y 16; Obras de San Agustín, tomo XV, ed. Balbino Martín O.S.A., Biblioteca de Autores Cristianos, Madrid 1947, p. 1195 y 1197. 
del cosmos y de la historia en sus múltiples sentidos y niveles de lectura (24) en tanto son obras de Dios: el mundo y el hombre son para Hildegard un texto que hay que descifrar y comprender, son también un liber divinorum operum (25).

Recordemos aquí, en relación con esta idea del mundo como libro y como espejo, los versos atribuidos al poeta y teólogo Alain de Lille (siglo XII) sobre la 'legibilidad' del mundo y sus creaturas, como en un espejo, así como sobre la mortalidad humana y lo pasajero del mundo:

"Omnis mundi creatura /quasi liber et pictura / nobis est speculum./Nostrae vitae, nostrae mortis, / nostri status, nostrae sortis / fidele signaculum” (26)

Es posible quizás alcanzar una mejor comprensión de la obra visionaria de Hildegard a partir de la tradición teológica propiamente monástica y de la elaboración de los conceptos asociados con la "mentalidad simbólica" en los términos utilizados por Chenu (27) y por Rauh (28) respecto de las obras de autores del siglo XII que relacionaron Naturaleza y Creación, Literatura y Biblia, Sacramento, Liturgia y comunidad eclesial, mediante los procedimientos básicos de la analogía, entendida aquí en el sentido amplio de las correspondencias simbólicas (29). En este contexto, podemos asumir la pertinencia de la definición de símbolo propuesta por un coetáneo de Hildegard, el maestro de teología Hugo de San Víctor, quien fue el autor de un comentario de la Jerarquía celeste, una de las obras fundamentales del Pseudo-Dionisio (s.V), y aseguró su recepción en el siglo XII. Para Hugo, "Símbolo es la conjunción, es decir la correspondencia de las formas visibles con la manifestación de las proposiciones sobre las realidades invisibles" (30).

(24) Nos referimos aquí a las lecturas literal, alegórica o espiritual e intelectual, de acuerdo a las definiciones consagradas de la exégesis medieval y que tienen su punto de partida en al autoridad de San Agustín: se trata para él de tres modos de comprensión de las Escrituras: corporale, spirituale, intellectuale (ver supra n. 22).

(25) Para el simbolismo del mundo como libro, cf. Curtius, E.R., European Literature and the Latin Middle Ages, Harper \& Row, New York and Evanston 1953 (1948): cf. esp. el capítulo titulado 'Poetry and Philosophy' (pp. 203-213). Existe una vasta literatura sobre esta relación simbólica en la literatura medieval.

(26) Alanus de Insulae Opera, PL 210, 579 AB: "Toda creatura del mundo, como libro y pintura es para nosotros un espejo, señal fiel de nuestra vida, de nuestra muerte, de nuestra condición, de nuestra suerte" (Trad., María Isabel Flisfisch).

(27) M.-D. Chenu, La Théologie au douzième siècle, Librairie Philosophique Vrin, Paris 1957, esp. Pp. 159-209, en el capítulo VII, denominado "La mentalité symbolique". Lo que Chenu entiende por "mentalité" lo expresa así: "cette impregnation plus ou moins consciente des modes et tours de pensée, cette coloration des notions les plus communes, cet ensemble de postulats, rarement exprimés, par tous et partout consentis, difficiles à découvrir " (p. 161).

(28) Rauh, Horst Dieter, Das Bild des Antichrist im Mittelalter: von Tyconius zum desutschen Symbolismus, Verlag Aschendorff, Münster 1973, esp. pp. 9-18, 165-178.

(29) Ver también en este contexto el estudio de Erich Auerbach, Figura, Mínima Trotta, Madrid 1998. Como recuerda también Rauh (ver supra, n. 19, p. 13-14), la imagen de la Historia para los simbolistas es figural: el rey David refiere a César Augusto y Carlomagno, y Ciro a Constantino; la Sinagoga prefigura a Ecclesia y esta, a su vez, es el símbolo real de la Nueva Jerusalén. En el ámbito del mal, Faraón y Diocleciano, Saúl y Herodes, Nerón y Enrique IV están en la serie de tiranos que preceden al Anticristo.

(30) Expositio in Hier. Cael. III, INIT. PL 175, 960, cit. por Chenu, op. cit. p. 162; cf. también p. 167. 
De este modo podemos comprender quizás más adecuadamente la contemplación de "los misterios celestes" y de la belleza del mundo en cuanto creación divina - recordamos en este punto el texto de Isaías que hemos citado como epígrafe y que Hildegard comenta en el $L D O$ (31) - vista esta contemplación como una actividad exegética que encontramos explicitada en la obra más madura de Hildegard, es decir en el $L D O$ y en otros textos epistolares compuestos por ella hacia finales de su vida, particularmente en su carta de 1175 al joven monje Guibert de Gembloux (32).

\section{LA ESTRUCTURA Y LOS TEMAS DEL LDO}

En cuanto a su estructura, el $L D O$ consta de diez visiones distribuidas en tres partes. En la primera parte se desarrolla una serie de cuatro visiones cosmológicas (33) que incluyen las relaciones entre el macrocosmos y el hombre como microcosmos (34) y que culminan con el comentario al Prólogo del Evangelio de San Juan: "En el principio era la Palabra..." (Juan 1, 1). La segunda parte comprende una sola gran visión, donde se describen la tierra y los méritos de la vida; una suerte de geografía de los lugares de bienaventuranza, de las almas en el purgatorio y el lugar de la condenación eterna; en la segunda parte de esta visión se elabora el tema de los "siete días de la creación" (35); se nos presenta asimismo a continuación un conjunto de visiones sobre los diversos ámbitos de la creación divina y en la tercera parte -constituida por cinco visiones- Hildegard desarrolla los temas de la ciudad de Dios, la acción de Sapientia y Caritas en la historia, y las edades del mundo antes de la venida del Anticristo y el fin de los tiempos (36).

(31) LDO, I, 2, 45 (Derolez / Dronke, p. 110).

(32) Ep. CIII, Hildegardis Bingensis Epistolarium, ed. Van Acker, CCCM 91 y 91 A, Brepols, Turnhout 1991-1993, pp. 258-265.

(33) Monika Klaes realiza un estudio detallado de los temas cosmológicos en el Scivias y en el LDO en su "Zu Schau und Deutung des Kosmos bei Hildegard von Bingen", en Adelgundis Führkötter, ed.: Kosmos und Mensch aus der Sicht Hildegards von Bingen, Mainz 1987, Verlag der Gesellschaft für Mittelrheinische Kirchengeschichte, pp. 37-124 (p. 79). Un estudio anterior en el que se compara la cosmología de Hildegard con la de Honorius Augustodunensis y otros autores es el de Barbara Maurmann, Die Himmelsrichtungen im Weltbild des Mittelalters. Hildegard von Bingen, Honorius Augustodunenis und andere Autoren. München, Wilhelm Fink Verlag, 1976. Una comparación importante entre los temas cosmológicos del $L D O$ y la obra científica de Hildegard debería hacerse en el marco de una investigación sobre la debatida autenticidad del Ms Cause et Cure atribuido a Hildegard: cf. la introducción a la reciente edición crítica realizada por Laurence Mouliner: Beate Hildegardis Cause et cure, Akademie Verlag, Berlin 2003, pp. XI-CXVII.

(34) Hay que anotar, sin embargo, que Hildegard no utiliza estas expresiones 'consagradas' en su obra, sino las de 'mundo' y 'hombre'.

(35) Para un estudio comparativo de este tema, ver Johannes Zahlten, Creatio mundi. Darstellungen der sechs Schöpfungfestage und naturwissenschaftliches Weltbild im Mittelalter, Klett-Cotta 1979 (Stuttgarter Beiträge zur Geschichte und Politik, Bd. 13). Este importante tema se entronca por cierto en la enseñanza bíblica judía, con la exégesis patrística (en particular con las eneseñanzas de San Augustín) y se puede comparar la enseñanza de Hildegard con la de otros importantes escritores del siglo XII: Honorius Augustodunensis ( $1^{\mathrm{a}} \mathrm{mitad}$ siglo XII), Hugo de Saint-Victor (m. 1141), Petrus Lombardus (1095-1160), Rupert de Deutz (1070-1129) y Pedro Abelardo (1079-1142).

(36) Un estudio clásico del pensamiento escatológico de Hildegard como la última de los 'simbolistas alemanes' es la ya mencionada obra de Horst Dieter Rauh, Das Bild des Antichrist im Mittelater: von Tyconius um deutschen Symbolismus, Verlag Aschendorff, München 1973, esp. el capítulo VII, "Hildegard von Bingen" pp. 474-527. 
La descripción de los principales temas de esta obra visionaria nos ayuda a situarla en el contexto de las preocupaciones centrales de los filósofos y teólogos del siglo XII, si bien sabemos que las relaciones precisas de la obra de Hildegard con la de sus contemporáneos son objeto de un debate probablemente sin solución (37). Como lo plantean M.-A. Chenu (38) y Tullio Gregory (39) en sus estudios sobre el platonismo medieval, y como lo planteó asimismo Rauh en su obra sobre los simbolistas alemanes de la Edad Media (40), se produjo en los autores del siglo XII un acercamiento a la naturaleza y la historia desde perspectivas creativas que intentaron conciliar las lecturas del Timeo de Platón, de Boecio, del Pseudo-Dionisio a través de Scoto Eriugena, con la exégesis bíblica, y este acercamiento produjo una gran diversidad de obras cosmológicas y teológicas de gran complejidad y riqueza.

En este ámbito debemos considerar el $L D O$ de Hildegard, puesto que en él encontramos el tratado cosmológico, la exégesis bíblica, la topografía de la salvación y la condenación, las edades del mundo y la discusión sobre la creación del mundo y el final de los tiempos, además de la intervención en la Historia de dos grandes manifestaciones divinas, Sapientia y Caritas, fuerzas amorosas que han creado y sostienen el mundo.

En la obra de Hildegard, la "contemplación" y la "revelación de los misterios" se hace escritura en los ciclos de relatos de una visión/audición (experiencia de ver y escuchar fundamentales en la preceptiva medieval de la comprensión de la realidad (41)) y se hace imagen visionaria gracias también a la presencia -importantísima en algunos de los manuscritos del Scivias y del $L D O-$ de las representaciones iconográficas de las visiones, con las cuales las palabras establecen un diálogo (42). Palabra e imagen (43), (palabra que se refiere a una imagen visionaria e imagen

(37) Zöllner, M., op. cit., p. 271.

(38) M.-A. Chenu, La théologie au Douzième Siècle (Cf. supra, n. 9), esp. el cap. V, “ Les platonismes du XIIème siècle ", pp. 108-141.

(39) Cf., su capítulo "The platonic inheritance" en P. Dronke, ed., A History of Twelfth-Century Western Philosophy, Cambridge University Press, Cambridge 1988, pp. 54-78.

(40) Cf. Rauh, op. cit. ver supra n. 28.

(41) Para una completa revisión del Ver y el Escuchar en la Edad Media alemana y para un estudio de la comprensión de la realidad en los ámbitos de la religión, el derecho, la literatura y la vida cotidiana, así como para una poética de la visualidad, ver el importante estudio de Horst Wenzel, Hören und Sehen. Schrift und Bild.. Kultur und Gedächtnis im Mittelalter". C. H. Beck, München 1995.

(42) Recordemos en este contexto una afirmación de W. J. T. Mitchell: "The dialectic of word and image seem to be a constant in the fabric of signs that a culture weaves around itself. What varies is the precise nature of the weave, the relation of warp to woof. The history of culture is in part the story of a protracted struggle for dominance between pictorial and linguistic signs" (Iconology: Image, Text, Ideology, University of Chicago Press, Chicago 1986, p. 43). Para un estudio de las imágenes en el Scivias, cf. Lieselotte E. Saurma-Jeltsch, "Die Rupertsberger Scivias-Handschrift: Überlegungen zu ihrer Entstehung" in Hildegard von Bingen: Prophetin durch die Zeiten, E. Förster, ed., Freiburg i. Br. 1998, pp. 340-358 y sobre todo, Die Miniaturen im 'Liber Scivias' der Hildegard von Bingen: Die Wucht der Vision und die Ordnung der Bilder, Wiesbaden 1998; Christel Meier, "Calcare caput draconis. Prophetische Bildkonfigurationen in Visiontext und Illustrationen: zur Vision 'Scivias' II, 7" in Hildegard von Bingen: Prophetin durch die Zeiten, pp. 359-405; un estudio interpretativo de las imágenes del LDO, en esta misma compilación, es el de Ingrid Riedel, "Hildegards Sophia-Vision. Zu einer Miniatur aus dem Lucca-Kodex" pp. 406-418.

(43) Para la relación palabra/imagen y especialmente para una consideración de la ekphrasis o representación verbal de representaciones visuales, cf. el sugerente libro de W. J. T. Mitchell, Picture 
pictórica que a veces contradice a las palabras escritas o las lleva más allá de su aparente sentido inicial (44)) colaboran, cada una desde su campo específico, en estos textos que afirman ser la escritura de una experiencia de ascenso espiritual que implica la visión y la audición con los sentidos interiores y que -también por voluntad divina- deberá ser escrita y reescrita a lo largo de la vida de su autora. El mandato de la escritura -como en los textos proféticos del Antiguo Testamentohace de la experiencia interior un 'envío', un mensaje que debe ser entregado a otros.

\section{EL MANDATO DE LA ESCRITURA EN EL LIBER DIVINORUM OPERUM}

En su prólogo a este tercer corpus de textos visionarios que nos ha llegado en seis manuscritos completos y un fragmento (45), Hildegard afirma que, en un momento especialmente crítico de la vida de la Iglesia y del Imperio, "en el año 1163 de la Encarnación del Señor, cuando la presión de la sede apostólica bajo Federico, emperador de la autoridad romana, todavía no se aquietaba, una voz del cielo" se dirigió a ella diciendo:

"Oh pequeñita forma, que eres hija de muchísimas labores y atormentada por graves enfermedades del cuerpo, pero sin embargo inundada por la profundidad de los misterios de Dios, encomienda estas cosas que ves con los ojos interiores y que percibes con los oídos interiores del alma, a la escritura firme para utilidad de los hombres; para que los hombres comprendan a su creador a través de ella y no eviten venerarlo con digno honor. Por consiguiente, escribe estas cosas no según tu corazón, sino según mi testimonio, [Yo] que soy la vida sin comienzo ni fin, y no [las escribas] inventadas por ti ni premeditadas por otro ser humano, sino predestinadas por mí antes del principio del mundo; puesto que así como presentí al hombre antes de ser creado, así también preví aquellas cosas que le son necesarias" (46).

Un poco más adelante, en el mismo Prólogo, se afirma asimismo el carácter testimonial de la actividad visionaria, que requiere además una vigilancia "en cuerpo y alma":

Theory. Essays on verbal and visual representation, The University of Chicago Press, Chicago \& London 1994. En particular, ver los capítulos "Visible Language: Blake's Art of Writing”, pp. 111-150 y "Ekphrasis and the Other" pp. 151-181.

(44) Cf. Horst Wenzel, op. cit. cap. VI. 2, "Zu Kongruenz und Konkurrenz von Schrift und Bild", pp. 296-301.

(45) Mansucritos: $\mathbf{G}=$ Gante, UB, Ms 241 (1170/74, Rupertsberg); $\mathbf{R}=$ Wiesbaden, HLB, Hs 2 [Riesencodex]; 1170/79, Rupertsberg; Tro= Troyes, Bibliothèque Municipale, Cod. 683 (1170/79 Rupertsberg); L= Lucca, Biblioteca Statale, Ms 1942 (1 ${ }^{\mathrm{a}}$ mitad siglo XIII, Renania); Tr= Trier, Stadtbibliothek, Ms 722/277 4 (1489, ¿Rupertsberg?; ¿Cartuja Beatusberg?); Lo= Londres, British Library, Cod. Add. 15418 (finales del s. XV, ¿Inglaterra?) Fragmento: F= Frankfurt a.M., Stadtund Universitätsbibliothek, Fragm. Lat. I 95 (S. XIII, origen desconocido).

(46) $L D O$, Derolez /Dronke Prologus, p. 45 (mi subrayado). Trad., María Isabel Flisfisch y María José Ortúzar (en preparación). 
“...Miré a lo alto hacia la luz verdadera y viviente [para saber] qué debía escribir; puesto que todo lo que había escrito desde el principio de mis visiones o todo lo que de allí en adelante sabía, lo vi en los misterios celestes, vigilante en cuerpo y alma, con los ojos interiores de mi espíritu y lo oí con los oídos interiores y no en sueños ni en éxtasis, así como [1o] mencioné en mis primeras visiones, y no todo lo que percibí desde el entendimiento humano lo percibí con la verdad como testigo, sino que percibí aquello que [está] en los misterios celestes" (LDO, Prólogo) (47).

En su ya mencionada carta al joven monje Guibert de Gembloux, escrita poco tiempo después de completar la escritura del $L D O$, Hildegard escribe que su espíritu asciende por la gracia divina y que su 'visión interior' (siguiendo en este sentido la definición agustiniana de la visión espiritual (48)) la lleva a contemplar costumbres y tierras lejanas:

"En la visión mi espíritu asciende, tal como Dios quiere, hasta la altura del firmamento y hasta el cambio de los diversos aires, y se esparce entre pueblos diversos, en lejanas regiones y en lugares que son para mí remotos. Y como veo estas cosas de este modo, las contemplo según el cambio de las nubes y de otras criaturas. No oigo estas cosas ni con los oídos corporales ni con los pensamientos de mi corazón, ni percibo nada por el encuentro de mis cinco sentidos, sino en mi alma, con los ojos exteriores abiertos, de tal manera que nunca he sufrido la ausencia del éxtasis.

(...) Lo que he visto o aprendido en esta visión, lo guardo en la memoria por mucho tiempo, pues recuerdo lo que alguna vez he visto u oído. Y simultáneamente veo y oigo y sé, y casi en el mismo momento aprendo lo que sé. Lo que escribo es lo que veo y oigo en la visión, y no pongo otras palabras que las que oigo. Lo digo con las palabras latinas sin pulir como las oigo en la visión, pues en la visión no me enseñan a escribir como escriben los filósofos. Y las palabras que veo y oigo en esta visión, no son como las palabras que suenan en la boca del hombre, sino como llama centelleante y como nube movida por el aire puro". (Carta a Guibert de Gembloux, 1175) (49).

\section{AUTORÍA Y TRADICIÓN PROFÉTICA, CONOCIMIENTO Y REVELACIÓN}

Los textos de los profetas del Antiguo Testamento, de San Juan en su evangelio y en el Libro del Apocalipsis atribuido tradicionalmente al mismo evangelista, son todos ellos referentes inmediatos y explícitos de la obra de Hildegard, y su lectura nos permite constatar cómo una experiencia visionaria, determinada en cada

(47) LDO, Derolez / Dronke, Prologus, p. 46; Trad. M.I. Flisfisch y M.J. Ortúzar (en preparación).

(48) San Augustín, De Genesi ad Litteram, XII, 6, 15 y 16; Obras de San Agustín, tomo XV, ed. Balbino Martín O.S.A., Biblioteca de Autores Cristianos, Madrid 1947, p. 1197.

(49) Ep. CIII, Van Acker, op. cit. pp. 258-265. Trad. V. Cirlot, Vida y Visiones, p. 166. 
caso por múltiples factores históricos y culturales, se constituye en una creación imaginal y verbal "canonizada" en el marco de una determinada tradición cristiana de 'revelación' (50). Por otra parte, la evolución de los contenidos y modalidades de esa experiencia visionaria tal como podemos recogerla en la escritura de una misma autora a lo largo de cuatro décadas, nos permite percibir los cambios, los descubrimientos y las innovaciones que se producen en esa escritura particular al mismo tiempo que en la tradición de escritura visionaria en un sentido más amplio (51).

De este modo, podemos asumir los problemas de autoría y tradición profética, revelación y conocimiento en una doble perspectiva al estudiar la obra de Hildegard de Bingen: la de la creación poética y simbólica característica de las cosmologías y de ciertos textos medievales como los bestiarios, así como de algunas de las obras literarias más relevantes del siglo XII y, por otra parte, la de los procedimientos exegéticos que se manifiestan en el 'registro escrito' de una voz divina que opera como elemento fundamental de una experiencia visionaria personal (vidi/ audivi). Como es previsible en la lectura de los textos, nos damos cuenta que esta "exégesis visionaria" (o "Lehrvision", "visión de enseñanza", en los términos de Hans Liebeschütz (52)) niega necesariamente, o al menos pone en cuestión, la autoría personal y el conocimiento humano individual para privilegiar la inspiración y la revelación divinas, pero necesita al mismo tiempo la escritura y la analogía como procedimiento exegético fundamental para poder comunicarse.

Por ello, al trabajar en el $L D O$ y en la obra visionaria de Hildegard en general, resulta particularmente difícil lograr una 'lectura unívoca' de una escritura monacal y femenina como la de esta autora, quien buscó y obtuvo una autorización eclesiástica y papal a fines de la década de 1140 y escribió desde entonces una obra en la que se presenta a sí misma como portavoz (femenina) de la Luz Viviente.

La reiterada afirmación de ignorancia por parte de Hildegard contrasta, por cierto, con su capacidad exegética en relación con los textos bíblicos, con la amplitud de sus conocimientos médicos y botánicos, y con la variedad de fuentes no citadas explícitamente por ella en el resto de sus escritos. En este último sentido, el rastreo que Angela Carlevaris realiza en su edición crítica del Liber Vite Meritorum (53) y el que Peter Dronke propone en su aporte a la correspondiente edición crítica del $L D O$ son ejemplares por la variedad de autoridades que posiblemente constituyeron fuentes directas o indirectas de la escritura de Hildegard. Al conocimiento de los libros bíblicos y de la patrística, hay que añadir la elaboración que ella realizó de una vasta literatura enciclopédica que a veces recupera información preveniente de Plinio y que Hildegard pudo conocer a través de Isidoro de Sevilla, tanto en sus Etymologie como en su De natura rerum, aunque no necesariamente en las fuentes, sino en compendios posteriores.

(50) Para un resumen de la tradición y la especificidad de los géneros literarios ligados a los testimonios de revelaciones y visiones desde la Antigüedad en Grecia y en Roma y más tarde en la Edad Media occidental, cf. Dinzelbacher, Peter: Revelationes, fasc. 57, Typologie des sources du Moyen Âge Occidental (Institut d'Études Médiévales, Louvain-la-Neuve). Brepols, Turnhout 1991.

(51) McGinn, op. cit, ver supra n. 12, pp. 338-349.

(52) Liebeschütz, Hans, Das allegorsiche Weltbild der Heiligen Hildegard von Bingen, Leipzig 1930, reimpr. Darmstadt 1964, con un epílogo del autor. Cf. Especialmente pp. 159-166.

(53) Hildegardis Bingensis: Liber Vitae Meritorum. Angela Carlevaris O.S.B., CC CM 90, Brepols, Turnholt, 1995 (Introducción). 
La ya mencionada afirmación de ignorancia corresponde, por lo tanto, más probablemente a una carencia de estudios formales (trivium y quadrivium) $\mathrm{y}$, sin duda, a la importancia otorgada, por ella misma y por su entorno más cercano, a la inspiración divina; la presencia privilegiada de la Voz divina se enfrentará pues con la voz de la "pobre mujer indocta" que ve y escribe por mandato las revelaciones celestiales.

En su trabajo pionero sobre este aspecto de la autorrepresentación de Hildegard en todos sus escritos, Hans Liebeschütz situó su obra, por una parte en la cultura latina del siglo XII y, por otra, intentó comprender la autorrepresentación de Hildegard como una "pobre e iletrada mujer" en el contexto del medio monástico y, en particular, en el de las lecturas recomendadas por la Regla de San Benito. En esta tradición, el conocimiento espiritual provenía más de la gracia y de la conversión que del estudio originado en las Escuelas, y no parece que este elemento estuviera en relación con el hecho de que Hildegard (femina indocta) fuera un mujer: en esta tradición monástica, hombres y mujeres se consideran igualmente ignorantes frente a la sabiduría divina.

La obra de Hildegard corresponde, sin duda y como ya hemos adelantado, al campo de la escritura de Revelación visionaria y profética, entendida esta última en el sentido medieval de capacidad de "interpretación inspirada" sobre el sentido de los tiempos y de la historia, así como de de los textos sagrados (54). Como diversos autores han enfatizado (55), Hildegard se definió a sí misma principalmente por este rol profético. Es en su aceptación del don visionario y en la proclamación de las revelaciones vistas con los "ojos interiores" que nuestra autora encuentra su identidad, buscada en la comparación con figuras bíblicas como Moisés y los profetas y, particularmente, con Juan Evangelista. La identificación de Hildegard con el Evangelista se produce en la contemplación de la luz divina, como leemos en un texto autobiográfico de la Vita (II, 16) y su cercanía a Juan se manifiesta asimismo en su comentario al Prólogo del Evangelio así como en su reescritura del Apocalipsis, tanto en el Scivias como en el LDO.

Por otra parte, la imagen visionaria (palabra/imagen) presente en sus escritos se propone de hecho a la imaginación y a la contemplación de los lectores. Como John de Salisbury (ca. 1115-1180) observaba, es la imaginación -y no el texto- la que abre la comprensión del lector a las cosas invisibles (Metalogicon

(54) Rabanus Maurus, In Epistolam I ad Corintios (PL 112, col. 116A): "Prophetas duplici genere intelligendus, et futura dicentes, et Scripturas revelantes..." (citado por McGinn, op. cit. ver supra n. 12, p. 338, n. 52).

(55) Peter Dronke, "Sibylle-Hildegardis. Hildegard und die Rolle der Sibylle" en Hildegard von Bingen, Prophetin durch die Zeiten, E. Forster ed. Freiburg-Basel-Wien, Herder 1997, pp. 109-125, Barbara Newman "Seherin-Prophetin-Mystikerin. Hildegard-Bilder in der hagiographischen Tradition" in Ibidem, pp. 126-152, Richard K. Emmerson "The Apocalypse in Medieval Culture" in The Apoclaypse in the Middle Ages, R.K. Emmerson and B. McGinn eds., Ithaca and London, Cornell University Press 1992, pp. 293-332; Bernard Mc Ginn, Hildegard of Bingen as Visionary and Exegete" (ver supra, n.12); Kathryn Kerby-Fulton "Prophet and Reformer" en Voice of the Living Light, Hildegard of Bingen and her World, Barbara Newman ed., Berkeley, Los Angeles, London, University of California Press 1998, pp. 70-90 y Victoria Cirlot ("Hildegarda de Bingen") en Victoria Cirlot y Blanca Garí: La Mirada interior. Escritoras místicas y visionarias en la Edad Media, Barcelona, Martínez Roca 1999, pp. 49-75. 
I.24.) (56). Como se sabe, la ilustración (illustratio) y la pintura (picturatio) eran un medio relativamente habitual de elucidación de su material doctrinal para muchos autores medievales (57). Estimulada por la imaginería, el alma del lector se vuelve a las imágenes almacenadas en la memoria (58) y en el proceso de selección de las imágenes deseadas, surge la imaginación. En este mismo sentido podemos suponer, como lo propone Karl Morrison, que el acto decisivo de la lectura en el siglo XII era lo que ahora denominaríamos visualización, y los lectores eran, en este sentido, espectadores (59). Un ejemplo adecuado para la comprensión de la importancia de la imagen y la imaginación para los autores (y lectores) medievales es la experiencia que nos propone el texto del libro del Apocalipsis sobre la lucha de los ángeles en el cielo (Ap 12). El abad Rupert de Deutz (60), (ca. 1070-1129) coetáneo de Hildegard como lo fuera John de Salisbury, se asombra del poder de la imaginación al transformar las palabras en un asombroso espectáculo de imágenes que aparecieron ante los ojos del alma de San Juan. Al leer nosotros las palabras del Apocalipsis, podemos recobrar la culminación del asombro y el temor de Juan gracias a la imaginación que surge de la meditación interior (61).

Creo que es legítimo considerar entonces la imaginación como una actividad surgida de las asociaciones de las imágenes almacenadas en la memoria, según las concepciones contemporáneas a Hildegard. En este sentido, podemos comprender quizás mejor la validez y la importancia de la "colaboración" de palabra e imagen (aun en su inevitable tensión) en tantas obras medievales y, en particular, en los escritos visionarios de esta autora. Un estudio ejemplar de las relaciones de las miniaturas con el texto visionario -en su doble dimensión de visión/ audición- lo

(56) The Metalogicon of John of Salisbury, trad. Daniel McGarry, Westport, CT: Greenwood Press, 1982, p66, cit. por Suzanne Lewis, Reading Images. Narrative Discourse and reception in the Thirteenth-Century Illuminated Apocalypse. Cambridge University Press, Cambridge 1995, p. 6.

(57) Cf. Mary Carruthers, The Book of Memory, Cambridge University Press, Cambridge 1990.

(58) Cf. el texto 'canónico' de San Augustín sobre las imágenes guardadas en la memoria: "Mas heme ante los campos y anchos senos de la memoria, donde están los tesoros de innumerables imágenes de toda clase acarreadas por los sentidos (...) Cuando estoy allí pido que se me presente lo que quiero, y algunas cosas preséntanse el momento; pero otras hay que buscarlas con más tiempo y como sacarlas de unos receptáculos abstrusos; otras, en cambio, irrumpen en tropel, y cuando uno desea y busca otra cosa se ponen en medio como diciendo: “No seremos nosotras?" (...) "Todo esto lo hago yo interiormente en el aula inmensa de mi memoria". Confesiones, X, 8, 12-13. Obras de San Augustín, tomo II, A.C.Vega O.S.A., ed., Biblioteca de Autores Cristianos, Madrid 1955 , pp. 481 y 482.

(59) Karl Morrison: History as a visual Art in the Twelfth-Century Renaissance, Princeton, Princeton University Press, 1990, p. 240-1, cit. por S. Lewis, op. cit., (ver supra n. 56, p. 6). En este mismo sentido, Anselmo de Havelberg, Dialogus 2.19 (PL 188, 1193) escribe que los lectores deberían contemplar los acontecimientos narrados en el texto "como sobre un escenario" (cit. por S. Lewis, op. cit., ver supra n. 56, p. 3).

(60) Rupert de Deutz, Commentarium in Apocalypsim VII.12 (PL 169 : 1050), cit. por S. Lewis,op. cit. (ver supra, n. 56, p. 6).

(61) Para una consideración de este tema en las canciones de la Symphonia, cf. Margot Fassler: 'Composer and Dramatist' in Voice of the Living Light. Hildegard of Bingen and her World. Ed. Barbara Newman, University of California Press, Berkeley \& Los Angeles, 1998, pp. 149-175; para la relación entre canto, imágenes y contemplación, cf. María Eugenia Góngora, "Feminea Forma and Virga: Two images of Incarnation in Hildegard of Bingen's Symphonia" in The Voice of Silence. Women's Literacy in a Men's Church, Thérèse de Hemptinne / María Eugenia Góngora, eds., Brepols, Turnhout, 2004, pp. 23-36. 
constituye sin duda el estudio de las imágenes del Scivias realizado por Lieselotte Saurma-Jeltsch (62). En este mismo sentido, podemos recordar los planteamientos de Suzanne Lewis en un artículo sobre el Apocalipsis gótico ilustrado inglés del siglo XIII:

"Las pinturas transforman las palabras [llevándolas] a otro ámbito de la realidad, llevando al lector desde la abstracción de los signos escritos (las palabras) hacia otro nivel de aprehensión en el cual la percepción óptica no solo verifica la autenticidad de la experiencia sino que determina la dirección [el sentido] de la comprensión del lector. La imagen del texto mediatiza la transición del lector desde la percepción de la página escrita e ilustrada hacia el ámbito del pensamiento y de las ideas, de la memoria y de sus asociaciones" (63).

\section{CONCLUSIONES}

Parece claro pues que se hace necesaria una consideración de las obras visionarias de Hildegard y del $L D O$ en particular en cuanto escritos cosmológicos y teológico-exegéticos, compuestos en el ámbito de la creación monástica y comparables a los escritos de similar carácter compuestos en el siglo XII. Es importante recordar asimismo que las miniaturas que acompañan los textos del Scivias así como del $L D O$ construyen también los sentidos posibles de la escritura de la visión /audición que su autora elaboró a lo largo de casi cuatro décadas de escritura.

Por otra parte, hay que situar su obra históricamente, en el contexto político y eclesiástico en el cual Hildegard influyó a través de su escritura visionaria y profética, incluyendo en este ámbito su epistolario. En este contexto y en relación con el carácter específicamente visionario de su escritura, podemos sugerir que el pensamiento contemporáneo que unió Naturaleza e Historia en una gran 'visión sacramental' (64) permitió que sus imágenes visionarias tuvieran la densidad, la recepción y, por sobre todo, el estatuto de veracidad que Hildegard logró establecer para su obra. Por último, y en este mismo sentido, es necesario destacar también la recepción de la obra de Hildegard en los siglos siguientes; es importante recordar que fue conocida sobre todo por sus escritos apocalípticos, recogidos en la antología compilada por el monje Gebeno de Eberbach hacia 1220 y reinterpretados, por cierto, de acuerdo a la coyuntura política y eclesiástica de cada momento. Si bien su influencia fue, en

(62) Lieselotte E. Saurma-Jeltsch, Die Miniaturen im "Liber Scivias" der Hildegard von Bingen, ver supra n. 40, esp. pp. 6-23, sobre el estilo, el ordenamiento y la función de las imágenes en ese libro.

(63) S. Lewis, "The English Gothic Illuminated Apocalypse, lectio divina, and the Art of Memory", in Word \& Image 7 (1991), pp. 1-32 (p. 3), cit. por Horst Wenzel, op. cit. p. 299 (mi traducción). En su Introducción a Reading Images (ver supra, n. 56), y en el apartado sobre hermenéutica y espiritualidad, S. Lewis repite estos conceptos en relación con las teorías de Robert Grosseteste (p. 10).

(64) Sobre las nociones de 'sacramento' como signo portador de sentido (ya sea personas o cosas, acontecimientos o ritos) que nos refieren a un misterio o verdad escondida, cf. de Lubac, op. cit., ver supra n. 9, pp. 399-400. 
definitiva, más restringida que la del abad Joaquín de Fiore y su pensamiento sobre las Tres Edades de la Historia de la Salvación, se puede considerar que la figura de Hildegard fue una de las más importantes y reconocidas en el ámbito del pensamiento profético y apocalíptico de la Edad Media.

\section{RESUMEN}

Este estudio es una revisión de los principales problemas que plantea la lectura de un libro de visiones como el Liber divinorum operum de Hildegard de Bingen (1098-1179).

Autoría, recepción y tradición profética, por una parte, y las relaciones entre 'imagen visionaria' y texto, 'revelación' y conocimiento, son algunos de los asuntos problemáticos que surgen de inmediato en la consideración de obras como el Liber divinorum operum, la obra cosmológica y profética más madura de esta autora.

Además de proponer posibles caminos de lectura e interpretación de esta obra, es imprescindible situar la obra de Hildegard en el contexto intelectual, político y eclesiástico en el cual ella influyó a través de sus cartas, su obra científica y, por cierto, su escritura explícitamente visionaria y profética. En este sentido hay que observar que, si bien su influencia fue, en definitiva, más restringida que la del abad Joaquín de Fiore y su pensamiento sobre las Tres Edades de la Historia de la Salvación, se puede considerar que la figura de Hildegard fue una de las más importantes y reconocidas en el ámbito del pensamiento profético y apocalíptico de la Edad Media.

\section{ABSTRACT}

This study is a revision of the principal problems that the reading of a book of visions, like Liber divinorum operum of Hildegard of Bingen (1098-1179), raises.

Authorship, reception and prophetic tradition, on the one hand, and the relationship among "visionary image" and text, "revelation" and knowledge, on the other, are some of the problematic matters that immediately arise from the consideration of works like Liber divinorum operum, the most mature cosmological and prophetic work of this author.

Besides proposing possible avenues of reading and interpretation of this work, it is essential to situate Hildegard's work in the intellectual, political and ecclesiastical context over which she had influence through her letters, her scientific work and, certainly, her explicitly visionary and prophetic writing. In this sense, it must be observed that, though it may be true that her influence was, definitively, more restricted than that of the abbot Joachim of Fiore and his thinking about the Three Ages of Salvation History, it can be considered that the figure of Hildegard was one of the most important and widely recognized in the field of prophetic and apocalyptic thought in the Middle Ages. 